\title{
Conflictividad ambiental en botaderos mineros de comunidades del Lago General Carrera. Retrospectiva desde actores locales de Aysén, Chile'
}

\section{Enviromental conflict in mining dumps of General Carrera Lake. Hindsights from Aysen settlers}

Klaus Martin Hennicke Laporte ${ }^{2}$ (1) y Luis Guillermo Davinson Pacheco ${ }^{3}$ (1)

\section{RESUMEN}

El presente artículo da cuenta de una investigación llevada a cabo el segundo semestre del 2019 en las comunidades de Puerto Sánchez, Puerto Guadal y Puerto Ibáñez, todas pertenecientes a la cuenca del Lago General Carrera, también conocido como Chelenko, en la Región de Aysén, zona austral de Chile. En ese marco, se aborda una problemática ambiental asociada al legado contaminante de relaves mineros que operaron en este territorio, en un pasado reciente. La situación descrita se relaciona con las prácticas históricas del extractivismo, así como también, con la forma de comportamiento del agente contaminante ("Violencia Lenta"). Dificultándose con ello la respuesta desde el aparato público, debido a la poca claridad respecto de cómo actúa dicho agente, y el desconocimiento existente respecto a los potenciales riesgos, que pudiera generar en la población y el ambiente, en el marco de lo que ha pasado a llamarse como "Desinformación Tóxica". Además, se analizan algunas de las reacciones ciudadanas, algunos efectos socioambientales y el manejo comunicacional sobre algunas actividades mineras, presentes y pasadas, en estas localidades del territorio adyacentes al Lago General Carrera.

Palabras clave: Conflictividad ambiental, ciudadanos, botaderos mineros, Lago General Carrera

\begin{abstract}
This article features on an investigation carried out in the second half of 2019 in the communities of Puerto Sánchez, Puerto Guadal and Puerto Ibáñez, all of them belong to the General Carrera Lake basin, also known as Chelenko, in Región de Aysén, southern zone of Chile. In this framework, is addressed an environmental problem associated to the polluting legacy of mine tailings that operated in this territory, in the recent past. The described situation is related to the historical practices of extractivism, as well as, with the behavior of the polluting agent (Slow Violence). Struggling with it the answer from
\end{abstract}

Fuentes de financiamiento: Proyecto "INFLUENCIA DE RELAVES EN CHELENKO: PROPUESTA DE REMEDIACIÓN" BIP 40010343, financiado con recursos del Gobierno regional de Aysén, a través del fondo de innovación regional FIC-R 2018, ejecutado por el Campus Patagonia de la Universidad Austral de Chile.

Investigador del programa de Biorremediación del Campus Patagonia de la Universidad Austral de Chile, Coyhaique, Chile. Correo electrónico: k.hennicke01@ufromail.cl

Académico Universidad de La Frontera, doctorante en Ciencias Sociales en Estudios Territoriales Universidad de Los Lagos, Chile. Correo electrónico: guillermo.davinson@frontera.cl 


\begin{abstract}
the public apparatus due to the lack of clarity about how this agent acts, and the ignorance about the potential risks, that could generate in the population and the environment, in the framework of what has come to be called toxic disinformation. Furthermore, some of the citizen reactions, some socio-environmental effects and communicational management of some mining activities, present and past, in these localities of the adjacent territory to General Carrera Lake are analyzed.
\end{abstract}

Keywords: Environmental conflict / citizens / mine dumps / General Carrera Lake

Más allá de algunas descripciones locales, de la vida cotidiana, que registró en los años 2000 el Vicariato de Aysén ${ }^{4}$, (jurisdicción territorial de la Iglesia Católica de la región de Aysén) no existen mayores estudios que den cuenta de la relación de los pobladores de estas localidades, con la antigua minería en la zona, menos aún con los pasivos ambientales existentes en estos lugares; también denominados relaves mineros. Si bien es cierto existen algunos estudios sobre "la antigua minería en la zona" estos no necesariamente tienen a las ciencias sociales como protagonista. Por ejemplo, el estudio de Evaristi y Miranda "Identificación de ex trabajadores que estuvieron expuestos a polvo en fracción respirable con contenido de Sílice, en las extracciones de las mineras ubicadas en Puerto Cristal" (2016) recoge interesantes datos acerca de la exposición de los trabajadores al polvo de sílice y sus efectos para la salud. Por otro lado, D Aubarede (1969) en "Evaluación de los conocimientos existentes sobre Cobalto, Manganeso, Mercurio Perlita, Plomo, Zinc y Zirconio" ayudó a conocer la presencia de dichos minerales en el territorio de la cuenca. Finalmente, Becerra y Pérez (2016) rememoran el valor arquitectónico patrimonial del poblado abandonado de Puerto Cristal en el artículo "Puerto Cristal: Valoración de un paisaje en ruinas".

Sin desmerecer la contribución de esta información, estas iniciativas corresponden más a informes solicitados desde organismos públicos tales como CORFO, Sernageomin, y otros ministerios, que a investigaciones desde la academia propiamente tal. De este modo, la baja existencia de estudios, más aún desde las ciencias sociales, en las localidades pertenecientes a la cuenca del Lago General Carrera de la Región de Aysén es evidente. Esta deficiencia investigativa, que es en general una deuda que tiene la ciencia social con la investigación en contextos rurales, motivó a un trabajo etnográfico, que, en el marco de una investigación socioambiental, de la Universidad de La Frontera en conjunto con el Campus Patagonia de la Universidad Austral de Chile, se enfocó en abordar el impacto de los botaderos mineros, pero desde la perspectiva de la ciudadanía. En este marco de escasa información, y escaso registro sociohistórico del pasado extractivista de la cuenca de lago y de la región en general, el artículo pretende abordar el legado contaminante de relaves mineros que operaron en este territorio, en un pasado reciente.

Agregar además que el artículo es un aporte que permite conocer las reacciones ciudadanas de los pobladores, algunos efectos socioambientales y el manejo comunicacional sobre estas actividades mineras, presentes y pasadas, en localidades del territorio adyacentes al Lago General Carrera. Dentro de los objetivos principales del presente artículo, se encuentra el análisis de un escenario de invisibilización y subvaloración de esta problemática socioambiental, que se ve agravada por darse en un territorio aislado; en el cual la expresión del agente contaminante (mediante el mecanismo de Slow Violence), dificulta la capacidad de acción ciudadana, toda vez

Hay que recordar que: "el 8 de mayo de 1955, el Papa Pió XII, por medio de la bula "In Amplitudine crescit" transforma la Prefectura de Aysén en Vicariato Apostólico" (Martínez, 2015: 22). 
que el mecanismo de contaminación es difuso y se presenta en un contexto sociogeográfico de alto aislamiento y bajo capital social, económico y cultural.

\section{Área de estudio}

\section{El poblamiento de La Región de Aysén}

La Región de Aysén es un territorio ubicado en el extremo sur de Chile. Según el Censo de 2017 del INE cuenta con algo más de cien mil habitantes distribuidos en 107.000 kilómetros cuadrados. Las difíciles condiciones geográficas y de conectividad de su territorio, han generado que la región sea una de las más aisladas, inaccesibles y menos pobladas del país. En este contexto socio geográfico el Estado, a partir de razones geopolíticas y militares impulsó su poblamiento, toda vez que post Guerra del Pacífico, Chile había perdido casi la totalidad de la Patagonia, lo que en parte explicaría esta necesidad estatal por poblar estos territorios y así evitar nuevas pérdidas territoriales. La estrategia inmediata fue la entrega de concesiones de terrenos a colonos, para la generación de canales de transporte marítimos y terrestres.

A finales del siglo XIX nacieron las Sociedades de Explotación, que contribuyeron al poblamiento de esta región ${ }^{5}$. Además, existió una segunda vertiente de poblamiento, a inicios del siglo $X X$, consistente en el arribo de chilenos que residían en la Argentina. Pese a los esfuerzos estatales y de los colonos, a finales de la década de 1920 solo un 10"\% del territorio de Aysén estaba ocupado; aun cuando ya habían pasado varias décadas desde las primeras expediciones a la región y ya existían centros poblados. Posterior al laudo Arbitral se consolidó una migración gobierno empresarial y otra espontanea; está última por estos colonos chilenos provenientes de Argentina. La migración espontanea suele ser subvalorada en la historiografía, pero comenzó a ser visibilizada en los años 30, principalmente por inmigrantes chilotes. Así, esta zona, ha sido bastión de una de las migraciones espontaneas más importantes del siglo $\mathrm{XX}^{6}$.

Por otro lado, la principal actividad económica de la región, en la década de 1930, seguía siendo principalmente la ganadería ovina fomentada por las grandes sociedades ganaderas presentes en este territorio. No obstante, presentaba atisbos de crisis. La" Guerra de Chile Chico" sumada a la poca rentabilidad del rubro ganadero; y a la conflictividad entre concesionarios y colonos, produjeron que diversas sociedades explotadoras, (del Baker, Industrial de Aysén, y otras) quebraran?

En ese escenario la actividad ganadera cayó estrepitosamente; y por ende la región quedó sin una actividad productiva fuerte sobre la cual sostener su sistema económico. Lo anterior, hacía menester diversificar la alicaída economía regional, situación que se agudiza con los efectos de

\footnotetext{
Para más información, remítase a http://www.manquehue.org/patagonia-area/el-poblamiento-de-aysen/ (02-05-2020.11:50hrs)

"Las compañías concesionarias y los pobladores espontáneos. Las compañías tuvieron su origen en una concesión del gobierno, estaban respaldadas por un gran número de accionistas que aportaban el capital y tenían por objeto producir riquezas para repartir entre estos. Los pobladores se originaron por su deseo de adquirir campos, los respaldaba su propia voluntad de trabajo y centraban su objetivo en lograr los medios para poder subsistir, y en algunos casos, poder prosperar" (Ibáñez, 1961: 312)

Para más información, remítase a http://www.memoriachilena.gob.cl/archivos2/pdfs/MC0012980.pdf (04-05-2020.12:05hrs)
} 
la crisis internacional de 1929, afectando a las materias primas de la región y el país. No obstante, este escenario adverso, en las montañas que bordean el Lago Carrera se encontraría la "solución" y es justamente en 1936, en los cerros de Puerto Cristal, donde se escribiría una parte de la historia minera de la región de Aysén, al descubrirse en un yacimiento de plomo y zinc que a la postre fue denominado como "Mina Silva" en honor a su descubridor ${ }^{8}$. Dicho yacimiento comenzaría a ser explotado en 1945 por la "Compañía Minera de Aysén"9. Pese al éxito inicial, la compañía ya había tomado la decisión de cerrar la mina a fines de la década de 1950 producto del rápido agotamiento de las reservas de mejor ley. Sin embargo, según informes de la época, Lahsen y Oyarzún (1966) el Estado, a través de CORFO, preocupado por la cesantía en la zona, decidió apoyar económicamente la actividad a través de la creación de la "Empresa Minera de Aysén". No obstante, esto las faenas entrarían en crisis durante la década de 1980, cerrando definitivamente en la década de 1990, fecha en la cual cierra el campamento minero de Puerto Cristal, y con ello finalizan cerca de 60 años de enclaves mineros en la cuenca del Lago General Carrera. Cabe señalar que el rubro minero en Aysén no tuvo la pujanza del Norte de Chile, si no que para esta realidad tuvo un carácter de estrategia de poblamiento. De este modo la minería en la zona fue una actividad altamente antieconómica, sin embargo, se sostenía dado que fue apoyada por el gobierno central, fundamentalmente a través de la Empresa Minera de Aysén (EMA), CORFO y otros organismos estatales ${ }^{10}$.

\section{Los sitios de relave minero en la cuenca del Lago General Carrera}

La provincia de General Carrera tiene una superficie de 11920 kilómetros cuadrados, y es habitada por apenas 7530 personas. En cuanto a su poblamiento, al igual que en otros territorios ayseninos, tales como el litoral, o las pampas de Balmaceda y Ñirehuao su espacio geográfico fue poblado a través de grandes sociedades concesionarias, que trajeron colonos para explotar la ganadería de la zona. Sin embargo, a mediados de la década de los 30 se descubrió la presencia de minerales en la zona (principalmente en los sectores que actualmente corresponden a los poblados de Puerto Guadal, Puerto Sánchez y Puerto Cristal), lo cual traería consigo la instalación de empresas mineras, que operarán en el territorio hasta mediados de la década de los 90.

En la siguiente imagen se observan los principales sitios de relave minero abandonados presentes en la cuenca del Lago General Carrera. La investigación abarcó a 3 de las 4 comunidades que se encuentran presentes en torno a los sitios de relaves visualizados en la imagen. El punto de color púrpura (Ex mina La escondida) se encuentra próximo a la localidad de Puerto Guadal, mientras que el punto de color rojo (Ex mina Las Chivas) se encuentra próximo a la localidad de Puerto Sánchez. Por otro lado, en color amarillo (Ex mina Silva) se encuentra cercano a la localidad abandonada de Puerto Cristal. Por último, en color morado y más hacia la derecha de la imagen

\footnotetext{
Para más información remítase a http://www.manquehue.org/patagonia-area/antolin-silva-ormeno/ (05-05-2020.10:15hrs)

"La mina Silva fue explotada por la Compañía Minera Aysén, que es el resultado de la sociedad formada por la Compañía Minera Tamaya, que es mayoritaria y Peña Royal (Compañía Disputada de Las Condes)" (Instituto de Investigación de Recursos Naturales (IREN), 1966.)

10 "La única explotación actual existente, la de la Empresa Minera Aysén, en el Lago General Carrera, es totalmente antieconómica y sólo se justifica por razones geopolíticas” (D'Aubarede, 1969: 23).
} 
se ve el sitio de relave "Laguna Verde" correspondiente a la ex minera "Cerro Bayo", la cual no fue considerada para esta investigación debido a que dicho sitio de relave no está abandonado aún.

Figura $\mathrm{N}^{\circ} 1$.

Localización de sitios de relaves mineros en la cuenca del Lago General Carrera
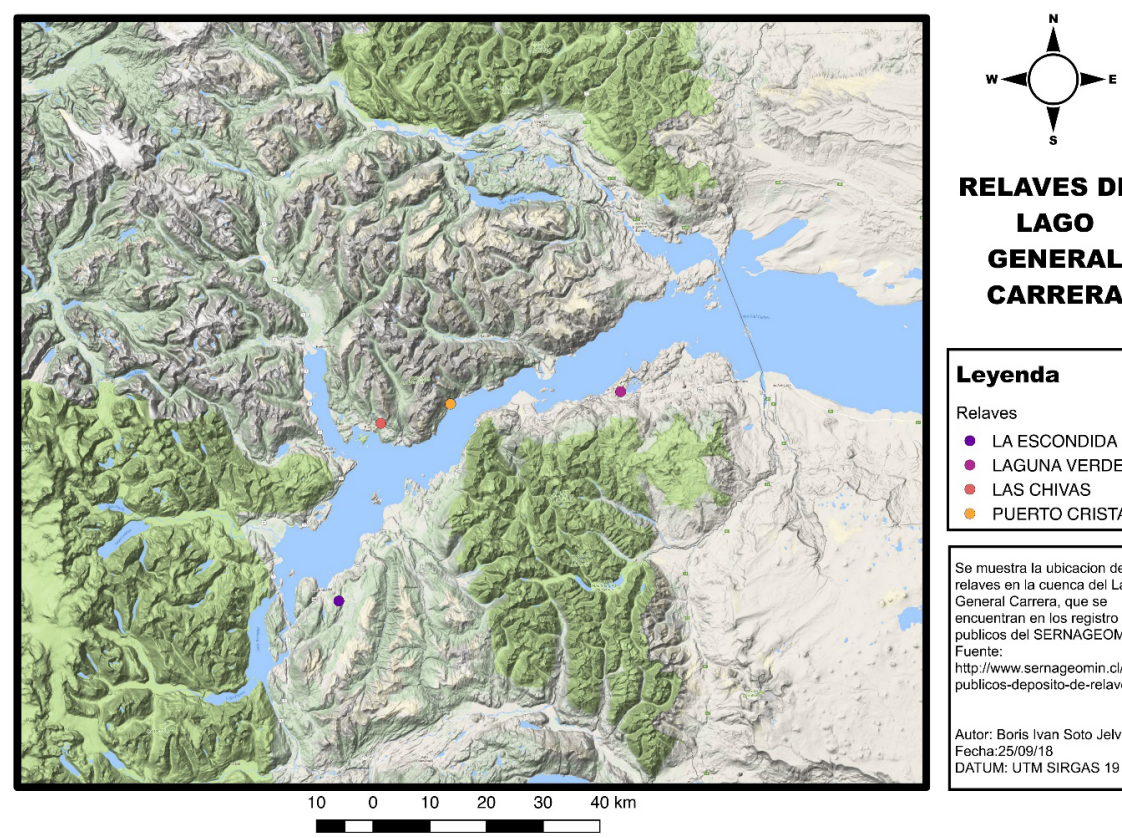

RELAVES DEL

LAGO

GENERAL

CARRERA

\section{Leyenda}

Relaves

- la escondida

- laguna Verde

- LAS chivas

- PUERTO CRISTAL

Se muestra la ubicacion de los relaves en la cuenca del Lago
General Carrera, que se encuentran en los registro

publicos del SERNAGEOMIN.
Fuente:
htt

hitp: //mww.sernageomin.cl/dato
publicos-deposito-de-relaves'

Autor: Boris Ivan Soto Jelvez

FATUM: UTM SIRGAS $19 \mathrm{~s}$

Fuente: Elaboración Propia

\section{Material y métodos}

Respecto de la metodología, hay que señalar que primó un enfoque investigativo de carácter cualitativo que se sustentó en el método etnográfico, que a través del trabajo de campo desarrollado el segundo semestre de 2019; consideró la aplicación de entrevistas semiestructuradas y grupos de conversación como principal mecanismo de recolección de datos. La investigación se inscribió en el marco del Programa de Magister en Gerencia Social de la Universidad de La Frontera, Temuco, y tuvo como objetivo principal "analizar la problemática ambiental de la Región de Aysén a través de efectos socioambientales, conflictividad ambiental y participación social generados por botaderos mineros en las comunidades y territorios que rodean al Lago General Carrera" (Tesis del Magister en Gerencia Social UFRO).

Además, en forma paralela al trabajo de campo, se procedió con la revisión de informes del Servicio Nacional de Geología y Minería SERNAGEOMIN ${ }^{11}$ y análisis de la prensa, tanto de medios regionales y nacionales asociados a la conflictividad ambiental en el territorio. Respecto a los

Entre los informes del Servicio Nacional de Geología y Minería que fueron analizados destacan; Anuario de la Minería de Chile 2017 e Investigación Geológica Minera Ambiental en Aysén. 
sujetos de estudio, se consideró a pobladores de tres localidades de la cuenca del Lago General Carrera, las que fueron, Puerto Sánchez, Puerto Ibáñez y Puerto Guadal respectivamente. En ese marco, se seleccionaron 12 informantes claves de cada pueblo, los cuales fueron sometidos a entrevistas semi estructuradas que fueron posteriormente procesadas con el Programa de Análisis Cualitativo ATLAS.ti. Agregar, a lo anterior, una serie de reuniones comunitarias, que, en orden correlativo, se materializaron en sedes sociales o lugares comunitarios en las propias localidades: Así se materializaron el 26 de mayo del 2019 (Museo Regional de Coyhaique); 15 de junio (Puerto Guadal); 2 de septiembre (Puerto Sánchez); 24 de septiembre (Escuela Aonikenk Puerto Ibáñez); 04 octubre (Puerto Sánchez); 15 octubre (Puerto Rio lbáñez) y 17 de octubre (Puerto Guadal) y 4 diciembre (Puerto Sánchez) respectivamente.

Las entrevistas a pobladores de Puerto Guadal y Puerto Sánchez, fueron realizadas en dichas localidades que se encuentran próximas a donde operaron las minerías. Sin embargo, para el caso del sitio de relave de puerto Cristal, los pobladores fueron entrevistados en otras localidades regionales (tales como puerto Ibáñez, y Chile Chico) ya que actualmente en Puerto Cristal, no quedan personas viviendo. En cuanto a las características de los entrevistados, se trató principalmente de antiguos pobladores que aún habitan la zona y que en la época de la antigua minería fueron perforistas o trabajadores administrativos de la minería o bien desempeñaron labores de apoyo secundarios en servicios de aseo limpieza, proveedor de alimentos, profesores de escuelas, etc.

\section{Resultados}

\section{Actores locales y sus perspectivas: La vigencia y ocaso del extractivismo}

Es posible constatar una serie de percepciones ambivalentes en los habitantes de la Cuenca del Lago General Carrera, respecto de las consecuencias que las faenas mineras implicaron para sus respectivos entornos. El extractivismo, en su acepción más tácita, sigue imperando en las lógicas cotidianas, no tan solo en estas localidades sino también en buena parte del territorio de Aysén. Un extractivismo, que se puede asumir como: "el proceso de extracción de recursos de la naturaleza para luego ser vendidos a las potencias industriales"; definición clásica, pero no por ello menos vigente, dado que ha imperado como premisa al definir el motor económico de la cuenca del Lago Carrera y la Región. En este sentido, se aprecian este tipo de valoraciones entre los habitantes locales, aun en la actualidad, arrojando sesgos de añoranzas a esos momentos percibidos como de "desarrollo" económico local, asociados a la minería. ${ }^{12}$

La tipología de estas percepciones vecinales, que hemos señalado, no han de extrañar dado que, tanto en el pasado como en el presente, la problemática ambiental de la Región de Aysén ha estado caracterizada por el debate en torno al modelo extractivista. Ejemplos de ello han sido los proyectos Alumisa en 1997; el hidroeléctrico Hidroaysén en 2011 y el de prospección minera Terrazas en 2018, los cuales han generado acaloradas discusiones en torno a la conveniencia de

\footnotetext{
El territorio "patagónico aysenino" se sigue concibiendo en el imaginario colectivo de los locales, como una región campesina ganadera; pese a que hace ya bastante tiempo, dejo esta de ser la principal actividad económica en la zona.
} 
la implementación de proyectos extractivos en esta zona austral..$^{13} \mathrm{El}$ eje sobre los cuales se han concentrado estas decisiones ha sido la dicotomía, "oportunidad / amenaza"; donde para los seguidores del modelo es una oportunidad de desarrollo (que se manifiesta en el aforismo de usar la riqueza que "nuestra" Patagonia nos da); en tanto los detractores lo refieren como una grave amenaza para la Patagonia (conservar la pristinidad natural que nos define como un lugar único en Chile).

La ciudadanía local, ha coexistido con la falacia del control ciudadano en las decisiones atingentes, no obstante, los hechos han revelado el rol de actores políticos y empresariales no residentes en la región y que finalmente, han sido quienes terminan zanjando estos aspectos (o como lo refieren en términos locales; "arreglándolo desde Santiago"). De este modo, no existiría, a nivel decisional una "Gobernanza Medioambiental", entendida esta como "la acción de gobernar y gestionar, a través de buenas prácticas y participación ciudadana, un medio ambiente y unos recursos naturales determinados". Para que dicho modelo decisional (la gobernanza local) sea posible, será clave concebir el "entorno como un todo", en el sentido de pensar al medio ambiente como un organismo vivo, imposible de ser racionalizado como una mercancía. Por otro lado, el incremento del capital político de las organizaciones sociales será vital para la construcción de un adecuado flujo de "Gobernanza Participativa", considerando que: "La Gobernanza Participativa o Buena Gobernanza, nace a partir de la democracia participativa, al combinar adecuadamente el principio de la representación y el incremento de la participación política de los ciudadanos" (Herrera, 2016: 2).

En la cuenca del Lago General Carrera esta ambivalencia y la pugna por el extractivismo no pasa desapercibida para su población, generándose distintas miradas y debates a escala territorial. Sin embargo, no es posible clasificar a la población local refiriendo solo a seguidores del modelo económico que podrían ser sindicados como pro economía de mercado; y detractores que podrían calificarse, como más bien puramente conservacionistas. Por el contrario, existen importantes matices que hacen que los sujetos se muevan entre posiciones puramente mercantiles y posiciones puramente conservacionistas ${ }^{14}$. En lo que respecta a las historias de vida de los residentes, existe una valoración retrospectiva, muchas veces contradictoria, de los efectos del rubro minero, ya que muchas veces los sujetos separan lo que fue el "trabajo minero" el cual trajo "alegría, dinero y vida" en estos pueblos, de lo que fueron los "relaves mineros", que implicaron contaminación ambiental e inclusos daños a la salud humana.

Estos procesos extractivos mineros generadores de residuos complejos, adquieren en los análisis una connotación de negatividad respecto del trabajo minero; ya que son sindicados como responsables de un conjunto de enfermedades para los lugareños tales como: silicosis, plombosis y otras alteraciones mentales. Agregar, también un daño al medio ambiente, que se representa principalmente en las aguas y suelos de la zona. Pese a lo anterior, algunos vecinos anhelan la

13 ALUMYSA megaproyecto de una planta reductora de aluminio de la minera canadiense Noranda; en tanto HIDROAYSÉN contemplaba la construcción y operación de cinco centrales hidroeléctricas a cargo de ENDESA y Colbún S.A. TERRAZAS, era una Prospección Minera, de la compañía minera RedHill Chile S.p.A. con 101 plataformas de exploración a 4 kilómetros de Puerto Ingeniero lbáñez.

14 Al respecto: "Mire yo por un lado pienso que, si y por otro lado pienso que no, y pienso que si puede volver la minería porque la gente está toda empeñada en que haya trabajo, pero pensando distinto también está la otra parte del medio ambiente [...] En Chile Chico prometieron muchas cosas de parte de minería, que no se cumplieron y quedó como está. Que quedó como un desierto más" (Pobladora localidad de Puerto Sánchez). 
antigua minería, pero al mismo tiempo, se manifiestan críticos, con respecto a las formas en que se manejaron los procesos de producción en los relaves mineros; así refieren " se vivía ahí en un ambiente bien contaminado, o sea la chancadora, toda esta cosa donde se molían piedras, los mismos olores que salían ahí de la química de los químicos que estaban trabajando, era un ambiente contaminado, era un ambiente donde uno sabía que algo tenía que tener" (Poblador localidad de Puerto Ibáñez).

También se advierten sectores que rememoran con añoranza esa "minería de antes", pero no desearían que esta actividad retorne a la zona, ya que se impone el aforismo que "los tiempos cambiaron". En este sentido, quienes estuvieron "más ligados al rubro minero de manera directa" como perforistas y cateadores refieren un discurso más favorable e incondicional con respecto a la actividad minera; y también reconocen riesgos de la actividad, pero los justifican porque son parte del "quehacer minero", no constituyendo una situación problema ${ }^{15}$. En tanto, quienes se vinculaban de manera más indirecta, es decir, quienes, aun siendo parte de esta actividad económica, no entraban directamente a los socavones de la mina, (administradores, profesores, cocineras y limpiadoras), muestran posiciones más mixtas con un apoyo menos irrestricto hacia la actividad. Para estos sujetos, los riesgos ambientales y sanitarios son externalidades negativas que, de algún modo, sí empañaron esta actividad, generando en ellos un discurso que critica dichas situaciones acontecidas. De esta manera reconocen al minero "agallado" como un legado valioso, pero también concuerdan en que esta forma de trabajar fue perjudicial para ellos en la salud.

Por otro lado, los "expertos" manifiestan una clara oposición hacia todo tipo de minería y un cierto grado de comprensión por esa "minería de antes". En este sentido, asumen una perspectiva de comprender que esta actividad fue importante en ese momento para la región; e incluso valoran su legado patrimonial e histórico, pero focalizan su relato en las externalidades negativas asociadas fundamentalmente a la herencia de relaves mineros en la zona, los cuales a su juicio contaminaron y siguen contaminando el entorno.

A su vez el conjunto de quienes podemos definir como conservacionistas y empresarios turísticos, suelen tener posiciones que sustentan los mayores grados de oposición, focalizando sus preocupaciones en el estado y preservación de la flora y fauna nativa; más que en los supuestos aspectos "positivos" que pudo haber arrojado la antigua minería. Reconocen cierto valor patrimonial e histórico de esa actividad, pero enfocándola como un "error histórico" que no debe ser repetido bajo ninguna circunstancia. Un poblador de Puerto Guadal lo expresa en "la minería en la región fue parte de la historia y la historia no puede negarse, siempre la historia tiene que valorizarla para que no nos vaya mal. Entonces uno podrá decir que tuvo muchas externalidades, pero ahí está y sin duda fue importante". En síntesis, las percepciones de los actores antes descritas, revelan ambivalencias y tensiones, remembranzas y negatividades; no obstante, la excepción pareciera estar representada por aquellos actores que podemos circunscribirlos como conservacionistas y perforistas, quienes fijan su posición desde una plataforma más polarizada, sin ambigüedades, de rechazo o defensa, respectivamente respecto a lo que fue esta actividad extractiva.

El peligro no sería ni bueno ni malo para los pobladores, sino tan solo un "gaje del oficio", el cual sería bien sorteado por el minero quien en palabras de los pobladores sería una persona "agallada" (que no se amilana ante los riesgos de los explosivos y de la actividad minera en general). 


\section{Mecanismos de respuesta comunitarios}

En la actualidad, es necesario conocer ese conjunto de mecanismos comunitarios que han operado para enfrentar las consecuencias de esta problemática ambiental, representada por los relaves mineros, que han estado presente durante décadas en este territorio. En ese marco, se constata que los pobladores de las comunidades que rodean el Lago General Carrera presentan mecanismos de respuesta adaptativos que surgen más bien, desde la convivencia cotidiana con el agente contaminante $y$, no necesariamente, desde información objetiva o técnica sobre estos tópicos.

De este modo, las estrategias empleadas son producto de la observación y de razonamientos cotidianos, en ese marco, aparecen analogías de comparación ("si algo les hace mal a las plantas, es también posible, que haga el mismo efecto en las personas"). A nivel práctico, estos pobladores intentan evitar que su ganado beba agua contaminada con los desechos de los relaves mineros. Es un mecanismo ejemplificador de como los actores locales, si bien no se movilizan en la lógica tradicional del reclamo público, tampoco son indiferentes en su accionar frente a estos efectos ambientales negativos que están presentes en su entorno. En la localidad turística de Puerto Guadal, la Junta de Vecinos se interesa por conocer los resultados de muestreo de presencia de metales pesados, lo que evidencia que es una temática que les preocupa.

Por otro lado, los mecanismos de movilización ante este conflicto ambiental en particular son menores que en otros casos ocurridos en la región; como Hidro-Aysén, por ejemplo; y ello, obedece entre otros factores, a un déficit de actores ambientales gravitantes, es decir, conservacionistas de alto capital sociocultural, que fueron quienes desplegaron esfuerzos políticos, sociales y económicos como ocurrió en el caso del conflicto por el proyecto HidroAysén. Estos sucesos acontecidos en esta zona, en los cuales el ambientalismo actúa solo en casos de crisis, pueden ser explicados bajo el concepto de "ambientalismo occidental". Para Martínez Allier (2004) este denominado "Ambientalismo Occidental" consiste en un mecanismo reactivo para enfrentar situaciones de crisis y no en un cambio en la conciencia humana. Por consecuencia, las respuestas emanadas del Ambientalismo Occidental; (ecoeficiencia, capitalismo verde, etc.) siguen un racionamiento, en el cual más que velar por la sustentabilidad del planeta se vela por la sustentabilidad del modelo.

En este sentido, incluso los conservacionistas solo intervienen cuando están en juego intereses económicos y paisajísticos propios; eso explicaría la acción en el caso Hidroaysén, y la inacción en el caso "relaves abandonados". Además, Leff (1998) señala que el sistema tiene una tendencia inescapable al crecimiento y que no es capaz de detener la degradación que genera. "El neoliberalismo ambiental busca debilitar las resistencias de la cultura y la naturaleza para subsumirlas dentro de la lógica del capital. La participación ciudadana se hace ficticia ya que no se da espacio hacia voces disidentes del capitalismo sustentable" (Leff, 1998: 26). Debido a esto, solo se incorporarían las voces de actores ambientalistas que forman parte de cierta élite regional y nacional; dejando fuera del debate a otros actores incapaces de tener dichas influencias ${ }^{16}$.

En poblados como Puerto Ibáñez y Puerto Guadal, existen actores conservacionistas, sin embargo, son poco validados por el sistema político al tratarse de poblados pequeños. Para los pobladores, el hecho de no ser atractivos electoralmente haría que sus voces no sean escuchadas por las autoridades de turno. 
Por otro lado, a diferencia del mencionado proyecto hidroeléctrico, en los relaves mineros abandonados, la expresión material del problema ambiental contaminante (que, como, y donde) se encuentra difuso. Comenzado recién a ser abordado por equipos técnicos que se han interesado en estudiar la cuenca del Lago. Además, se debe tener presente que, a diferencia de dicho proyecto hidroeléctrico, la minería sigue siendo evaluada como una actividad económica que fue beneficiosa, en la cuenca del Lago General Carrera. Esta situación produce un impacto en la memoria colectiva de los lugareños, toda vez que tienden a minimizar ciertos impactos negativos producidos por las faenas mineras, lo cual se ve representando en frases como; "no, no, que pa que lo van a sacar si eso debe estar echo tierra ya pues" según una pobladora de Puerto Sánchez ${ }^{17}$.

Además, la "identificación de los sujetos" con la minería no se da debido a la actividad en sí misma, sino que se le "tiene apego" debido a que fue dicha actividad en concreto, un motor que pobló y trajo vida en dicho territorio, creando un dualismo y un relativismo difícil de resolver ya que "eso que contamina" también en su minuto trajo grandes progresos y beneficios a los habitantes del sector. Otro factor que inhibe o impide la movilización ciudadana en términos convencionales, en este caso, es el rango etario de estos pobladores, por un lado, por tratarse de personas que pueden ser calificados como de la tercera edad, lo que constituye un factor que ralentiza la protesta.

Este tipo de situaciones, de conductas disímiles asociadas al factor edad de los sujetos, es posible de explicar, por cierto, por las perspectivas, valoraciones o actitudes que las comunidades presentaban frente a las acciones extractivas contaminantes. Así, la actividad minera y las consecuencias de sus residuos en el lago no revestían una situación ambiental negativa o cuestionable, como se percibe y experimenta en la actualidad, y como ellos mismos refieren "en la época de los antiguos" el factor de preservación ambiental no estaba presente como una preocupación social y política. Esto último reflejado en la frase; "es que en ese tiempo no era un tema; uno no le daba importancia quizás por desconocimiento, el daño que se estaba causando al ecosistema" como lo refiere un vecino de Puerto Guadal.

En la actualidad, y contrariamente, a esos años, las cohortes de jóvenes y adultos jóvenes del territorio mayoritariamente manifiestan ciertos grados de preocupación por la temática ambiental; pero sobre todo destaca el concepto de "una identidad de la Patagonia", lo que motiva e implica que este territorio debe ser defendido y preservado de amenazas industriales externas. En un escenario como este, lo más probable es esperar reacciones de movilización en contra de futuras iniciativas mineras, que eventualmente pretendan instalarse en las localidades más pobladas, tales como Puerto Ibáñez o Chile Chico y en menor medida en Puerto Guadal o Puerto Sánchez debido a razones de tipo sociodemográficas.

En directa relación con lo anterior, se debe precisar que se habla de lo esperable de la movilización, pero no es algo seguro, ya que tal como señala (Ureta et al., 2018), los conflictos socioambientales no necesariamente generan que los actores sociales se movilicen. Muchas veces la incredulidad de que alguien vaya a hacer algo hace que las comunidades se inmovilicen. Desde esta perspectiva, la posibilidad de movilización solo es posible en caso de mediar una catástrofe de

Existe cierta creencia, de parte de algunos pobladores, de que el material del relave fue dañino pero que ya no lo es producto de que sus componentes ya se disolvieron en la tierra y las aguas del territorio. 
proporciones mayores, generándose con ello una respuesta a la conflictividad de carácter reactiva y no preventiva. Este mecanismo, que implica que las comunidades deben ser contaminadas durante décadas para que recién el Estado se anime a hacer algo puede ser explicado con el concepto de "violencia lenta"18. Lo anterior permite en parte zanjar la interrogante, sobre el porqué, dada la magnitud de la crisis ecológica y social, en muchas zonas de sacrificio, las comunidades no se manifiestan, ni tensionan en búsqueda de soluciones. Parte de la explicación se relaciona con la denominada "Incertidumbre toxica", que conduce a la inmovilización ${ }^{19}$.

\section{El Agente Contaminante y la Violencia Lenta}

Con el paso de los años, los relaves mineros en estos poblados de la Región de Aysén siguen dejando huellas materiales y simbólicas en los lugareños. Unos efectos más visibles que otros, dado que, en este caso, el agente contaminante presenta una forma de comportamiento, que la literatura define como violencia lenta (Slow Violence). Es decir, que el mecanismo de respuesta comunitario se hace más difícil de activar debido a que se desconoce a cabalidad el daño que se está generando, ni como este debe ser atacado en el lugar donde se está produciendo.

Bajo esta lógica el asunto de los relaves se convierte en un problema que no tiene la acción devastadora de una catástrofe de magnitudes, sino que por el contrario suele ser solo visible a través de una observación técnica ${ }^{20}$. De forma tal, que se torna bastante difícil generar mecanismos de acción social en torno a sus efectos, ya que la comunidad tiende a no movilizarse en torno a aquello que no percibe, y de lo cual solo se ha informado mediante rumores o estudios poco concluyentes. En este sentido la "desinformación toxica", entendida como la situación en la cual se sabe poco sobre cómo actúa el agente contaminante (en este caso sobre cómo pudiesen estar contaminados el agua y los suelos de la cuenca del lago), es un elemento que impide la movilización social en el sentido clásico.

Respecto a los sujetos afectados por Slow Violence, para Rob Nixon (2011), son siempre aquellos que viven en lugares más aislados y vulnerables y que tienen escasas redes de influencia para exigir soluciones a sus problemas. De esta forma, los ganaderos y antiguos pobladores de Puerto Sánchez y Puerto Guadal tienen poca capacidad de acción en este tema; de modo que, si se implementara una solución, es más probable que tengan más injerencia y, en consecuencia, mayores beneficios compensatorios, los grupos de conservacionistas y empresarios turísticos, que los pobladores antiguos de estos lugares.

\section{Reconocimiento de una problemática ambiental regional y zonal}

Pese a que la problemática de los relaves mineros ya lleva décadas en el territorio, se advierte un escaso reconocimiento a esta por parte de los habitantes de la Región Aysén. Misma situación

18 "Una forma particular de violencia ambiental " que ocurre gradualmente y fuera de vista, una violencia de destrucción retrasada que es [ampliamente] extendida en el tiempo y el espacio [...] Una violencia que no es ni espectacular ni instantánea, sino incremental y creciente, cuyas calamitosas repercusiones emergen en un amplio margen de escalas temporales" (Ureta et al., 2018: 339).

19 "Concepto bajo el cual se explica que ante la falta de claridad respecto a las fuentes de contaminación y los efectos de salud la capacidad de acción se ve mermada" (Ureta et al., 2018: 340).

20 La presencia de metales pesados es invisible al ojo humano, de modo que se necesitan cierto tipo de instrumental, que solo existen en universidades y centros de investigación, para notar la presencia de estos en los suelos. 
ocurre en general con los problemas ambientales, ya que para muchos habitantes estos tienen baja presencia en la región. En este marco, para comprender la problemática ambiental de la zona y sus efectos socioambientales, es imprescindible reconocer la existencia primero de una problemática ambiental regional y segundo de una problemática ambiental que se está dando en este territorio aledaño al lago.

En primer lugar, es importante "desmitificar" las posiciones que prevalecen acerca de la inexistencia de una problemática ambiental regional; y sobre todo de aquellos, que niegan la existencia de esta problemática de los relaves en la "cuenca del Lago General Carrera" y cuya posición se fundamenta en la observación prístina de la zona. De este modo es clave señalar que los relaves de la cuenca del lago son una manifestación más de los problemas socioambientales en la Patagonia, mismos que son reales, y que, si bien la región patagónica no presenta zonas de sacrificio todavía, esto no impide que pueda existir alguna en el mediano plazo. Por otro lado, desde un enfoque sistémico, para Vallejos (2017) la posibilidad de riesgos, asociados a proyectos de desarrollo extractivistas, es alta, debido a la poca capacidad de acción que tienen los sistemas sociales ante estas "nuevas" problemáticas. Bajo esta lógica los riesgos se evaluarán según la forma de observación que rija en dicho mundo, y como los riesgos socioambientales no tienen un mundo dentro del cual ser pensado, estos serán pensados y analizados desde los otros mundos (social, político, económico).

En segundo lugar, se tiende a percibir que la problemática ambiental en Aysén estaría exclusivamente localizada y visibilizada en la zona "norte" de la región, enfocándose principalmente en los problemas de contaminación atmosférica del "área de Coyhaique". A esto se agrega como problemática percibida, la contaminación del mar, producto de la "industria salmonera" que opera en los canales y fiordos de la zona norte de Aysén.

Si bien es probable que estos sean efectivamente, los problemas más visibilizados, no son los únicos y existen otros problemas que se avizoran en otras áreas del territorio regional. Una muestra de lo anterior, lo constituye, la situación de la cuenca, que como hemos referido, comprende una problemática ambiental propia, que trasciende los límites comunales, y que fue zona de desarrollo minero durante casi 60 años. De modo tal, que los relaves dejados por la antigua minería, los accidentes y las negligencias mineras que afectaron a la zona en las décadas del 2000 y 2010 constituyen a nuestro juicio, una problemática ambiental particular e importante para la Región de Aysén. A su vez, en esta área, se están sumando nuevas problemáticas socioambientales debido a un sector turístico que está en constante crecimiento y que genera nuevos desechos que van a dar al lago. A esto se le suma la falta de plantas de tratamiento de aguas servidas y servicios adecuados para una población flotante estival que crece año a año y que impacta sobre el entorno del lago ${ }^{21}$.

\footnotetext{
La contaminación por metales pesados en las aguas del lago, y los proyectos mineros en general no serían el único problema que afecta a la "cuenca del Lago Chelenko". Un profesional del área ambiental de Coyhaique al respecto: "eso no está estudiado y esa es mi hipótesis de que quizás en verano sobre todo en la fecha estival eh el lago tiene una carga impresionante, no solamente de nutrientes y de metales sino también de medicamentos, de químicos, de hidrocarburos y cosas que quizá ni siquiera alertamos a saber".
} 


\section{Los medios de comunicación social y la problemática ambiental}

En un contexto de aislamiento que dificulta contrastar in situ la problemática socioambiental de los relaves mineros, cobra importancia el rol que pueden desempeñar los medios de comunicación; dado que estos crean realidad a través de sus relatos. En estos contextos territoriales, los medios de comunicación son importantísimos, adquiriendo especial relevancia para la construcción de una determinada visión ciudadana en torno a las problemáticas ambientales de la zona.

En ese marco, es necesario indicar que, pese a ciertos sesgos y falta de profundidad en las materias difundidas, la información ambiental existe en los medios comunicacionales. De esta forma, es necesario desmitificar la premisa local de que "nunca sale nada de la zona en las noticias". A mayor profundidad, es necesario establecer que diversos medios nacionales y regionales cubren noticias relacionadas a problemáticas ambientales presentes en la zona. Recientemente, a modo de ejemplo, la cobertura del accidente de la Mina Cerro Bayo y sus consecuencias, la polémica apertura del Parque Patagonia y la fallida apertura del proyecto minero Terrazas, han ocupado un espacio en la agenda regional de noticias.

En relación con esta cobertura noticiosa, se aprecian ciertas falencias de los medios de comunicación en torno a cómo se aborda esta problemática ambiental; reflejando de alguna manera el planteamiento de Vallejos (2017) que refiere que la problemática ambiental no tiene un sistema mediante el cual pueda ser racionalizada, de modo que no existe un tratamiento especializado de este tipo de noticias en ningún medio comunicacional. De hecho, al identificar los principales tópicos comunicacionales es posible observar que "lo ambiental" pide, constantemente prestado raciocinios de otros sistemas (como el judicial, el económico y el social) para poder autoanalizar su propia problemática. Lo descrito anteriormente, establece una debilidad del sistema ambiental que irrumpe en el mundo social, pero que en la práctica aún no logra que sus problemáticas se integren de lleno al sistema social. Prueba de ello es que las líneas editoriales de los medios de comunicación se suelen dividir entre aquellas conservacionistas, que se preocupan casi exclusivamente de asuntos medioambientales y las de corte antropocéntrico economicista (preocupadas por la rentabilidad del negocio, el empleo generado y en menor medida por la integridad de los trabajadores.

Por otro lado, según el enfoque de Escobar (2014) "la irrupción de lo biológico en lo social" consiste en que el "tema ambiental" no puede estar disociado de los procesos y conflictos sociales que afectan a los territorios. De este modo lo "biológico" pasa a constituirse como hecho social de extrema relevancia para explicar la crisis del modelo civilizatorio ${ }^{22}$. Así, a diferencia de lo acontecido en décadas anteriores, donde los temas ambientales se reducían a problematizar componentes más bien ecológicos tales como la biodiversidad y la sustentabilidad, hoy en día distintas perspectivas intentan proponer una mirada más integral, buscando generar proyectos alternativos al desarrollo moderno, con objetivos de sostenibilidad y restauración. De este modo se asume una naturaleza que reviste características de un organismo viviente y que cualquier

\footnotetext{
El autor entiende por "Crisis del modelo civilizatorio" una situación en la cual la vida en un mundo moderno, individualista y neoliberal resulta cada vez más inviable. Se pone en cuestión incluso la racionalidad epistemológica del mundo moderno.
} 
efecto que en este sistema ocurra, repercutiría directamente sobre los organismos que en él residen ${ }^{23}$.

En síntesis, las problemáticas ambientales tanto en la zona, como en la región son una realidad concreta, e irrumpieron en la agenda noticiosa, como un hecho social. Sin embargo, aún no tienen una racionalidad propia. Será tarea de las ciencias repensar y construir una racionalidad ambiental acorde a las problemáticas ambientales actuales, las cuales se diversifican y están cada vez más presentes en la vida de los sujetos del territorio.

\section{Discusión}

Para los habitantes de las localidades de Puerto Sánchez, Puerto Guadal y Puerto Ibáñez, ubicados en la cuenca del Lago General Carrera en la Región de Aysén; subsiste en la actualidad un ideario comunitario de ser depositarios de un "legado ambiental". Esta transmisión de un patrimonio inmaterial, con contradicciones ambivalentes, reconocen en el fondo un origen, que se encuentra circunscrito a un momento histórico constitutivo que recuerda Jorge de 65 años de Puerto Guadal, "como comunidad, como pueblo fuimos creado por los campamentos mineros"24. Así, esto último se asocia a la instalación de un conjunto de actividades mineras (de cobre, plomo, zinc y oro) cuyas consecuencias menos abordadas corresponden a los desechos mineros, en formas de relaves, los cuales han afectado al entorno; principalmente a las aguas y suelos del Lago Carrera. Estos sitios de relaves mineros, que en un pasado reciente representaron el lado menos amable de una prolífera actividad minera de corte extractivista, están proyectando importantes efectos socioambientales en la actualidad. Efectos que trascienden lo exclusivamente ambiental-sanitario y están incidiendo sobre aspectos sociodemográficos, en indicadores tales como el despoblamiento, el aislamiento, la cesantía, la ausencia de actividades económicas importantes en la zona, etc.

Además, resulta interesante observar cómo los efectos del periodo de auge de la minería en la zona (1950-1995), han trascendido más allá de su propia esfera temporal, toda vez que el impacto socioambiental de las faenas mineras sigue siendo percibido, por sus habitantes, a casi 23 años del cierre del último enclave minero en la zona, específicamente Mina Cristal de Puerto Cristal en 1997. Dichos efectos no solo se expresan en aspectos y sucesos tangibles, como el despoblamiento de las ex localidades mineras, o la puesta en jaque de la inocuidad de los suelos y aguas de lago producto de la dispersión de los relaves mineros de la zona; sino que también en las subjetividades discursivas de los lugareños residentes de los poblados que rodean al Lago Chelenko - en ese marco, Bernarda (2019) pobladora de Puerto Sánchez, refiere: "Si, no había ninguna protección en ese tiempo, sacaban un par de guantes que le darian y botas de goma y nada más". Pero también, "toda la gente éramos muy unidos, siempre cuando salía uno en el tractor salíamos todos". - las cuales contienen la ya clásica dicotomía entre crecimiento económico y conservación ambiental, dicotomía que, pese a la tecnología existente, aún no ha podido ser resuelta completamente.

23 Durante la Cumbre de Rio De Janeiro 1992, los principales temas que estuvieron en la palestra fueron los de biodiversidad y sustentabilidad ambiental.

24 Carlos (2019) de 65 años, exprofesor, rememora el esplendor: "Un pueblo que, que, era el llamado Viña del Mar de lejos era impactante ver todas las luces que había ahi de la central hidroeléctrica que funcionaba en Puerto Cristal. Era bonito y desde lejos se veía un pueblo de bien". 
A su vez, el rubro minero estaba muy presente en los habitantes locales toda vez que se interrelacionaba con todos, los asuntos cotidianos de los habitantes del sector; y no tan solo con quienes tenían una vinculación directa, como eran los perforistas y administrativos de la empresa minera. Esta injerencia transversal de la minería en la cotidianidad incluía, además, a los profesores locales, comerciantes, policías, médicos, cocineras y todo aquel trabajador/a que se desempeñaban en el área de influencia de estos enclaves mineros. En un ámbito que Esterlina de Puerto Sánchez recuerda: "Era como una familia se juntaban todos y nadie se decía nada, era todo como una familia". De este modo, aun cuando el trabajo del lugareño no fuera la minería propiamente tal, la actividad extractiva incidía en su modo de vida. En ese marco, pese a que se aprecian distintas posiciones sobre los efectos del rubro minero, ningún lugareño se muestra indiferente a lo que fue dicha actividad; que incidió los proyectos vitales de todos aquellos que habitaron este territorio durante un largo periodo de más de 50 años. De manera que se puede afirmar sin temor a caer en exageraciones, que se produjo un hito con esta actividad productiva, es decir, existe un antes y un después de la minería en el territorio. Esto último, dado que el modelo extractivista aplicado en el Tercer Mundo no solo transforma las dinámicas económicas, territoriales y espaciales del lugar en donde se instala, sino que además transforma las identidades colectivas de los habitantes, generando con ello un sello en su discurso que es influyente a la hora de construir su propia historia de vida.

También es preciso señalar que a nivel regional la "Cuenca del Lago General Carrera" se configura como un territorio con una problemática socioambiental poco difundida y por ende escasamente comprendida; no tan solo por los déficits de información respecto a los mecanismos de comportamiento del relave en la zona, sino que, porque además sus dinámicas identitarias están todavía poco reconocidas, en una región que pareciese buscar olvidar su pasado ligado a esta cuestionada actividad. Esta actitud de negacionismo que predomina en los discursos oficiales en la zona, respecto del pasado minero reciente, se explica, en parte por la percepción y definición identitaria de un territorio de Patagonia prístina, concepción consistente con la proliferación del turismo en la zona, un turismo de intereses especiales, ecológico; discurso que se ve fortalecido por los efectos negativos que la minería trajo en la zona, tales como efectos contaminantes en el medio ambiente e impacto en la salud de las personas.

\section{Conclusión}

Para finalizar, la solución al problema ambiental en la zona, (que consistiría en retirar el material de relave existente en la cuenca del lago), se hace inviable toda vez que dicha acción requeriría una logística de proporciones debido a la gran cantidad de material de relave existente en la zona. Estas iniciativas solo pueden ser abordadas por grandes compañías mineras, muy distintas a las pequeñas y medianas que operaron en la zona. A esto se suma el hecho de que el rubro minero está prácticamente desactivado en la cuenca del lago, por lo cual no existe quien tenga los recursos ni la tecnología para hacer un cierre sustentable.

Sin embargo, pese a este escenario, si está "en manos" de los actores sociales y políticos regionales el no acrecentar aún más el problema ambiental en la zona. Para esto se deberá evitar a toda costa la instalación de nuevas faenas mineras, ya que los hechos han demostrado que sus pasivos (principalmente los relaves) quedan en el territorio por muchísimos años. Para lograr 
dicho objetivo será fundamental recuperar la memoria histórica, en el sentido de que será necesario reconocer el rol que jugaron las faenas mineras para el desarrollo de la zona; pero a su vez también resultará necesario debatir acerca de su viabilidad como modelo de desarrollo, teniendo en cuenta el pesado legado contaminante con el que cuentan a su haber. En esta misión será clave el papel que puedan jugar la ciencia natural y social, toda vez que estas se constituyen como un buen método para incentivar una identidad territorial que reconozca el legado de la actividad minera, pero que también sopese sus efectos menos deseables. Para ello será clave una ciencia social que dialogue con las comunidades y logre generar procesos de educación ambiental en sus habitantes más jóvenes.

\section{Referencias}

BECERRA, M. \& PEREZ, L. Puerto Cristal: Valoración de un paisaje en ruinas. Revista 180, 2016, Vol. 38, p. 1-7. http://www.revista180.udp.cl/index.php/revista180/article/view/318/305 *

D' AUBAREDE, G. Evaluación de los conocimientos existentes sobre Cobalto, Manganeso, Mercurio, Perlita, Plomo, Zinc y Zirconio. Santiago de Chile: Editorial Sociedad de Artes Gráficas Cepco Ltda, 1969.

ESCOBAR, A. Sentipensar con la tierra Nuevas lecturas sobre desarrollo, territorio y diferencia. Medellín: Ediciones UNAULA,2014

EVARISTI, C, MIRANDA, M. Identificación de ex trabajadores que estuvieron expuestos a polvo en fracción respirable con contenido de Sílice, en las extracciones de las mineras ubicadas en Puerto Cristal. Coyhaique: Servicios de Ingeniería, 2016.

HENNICKE, K,2020. Efectos socioambientales, participación social y conflictividad ambiental en botaderos mineros de comunidades del Lago General Carrera: Un análisis de la problemática ambiental de la región de Aysén. Tesis de Magister. Temuco, Chile: Universidad de la Frontera

HERRERA, G. La Importancia de la Gobernanza Participativa y su Incidencia en el Desarrollo Local. FCSH Opina Revista de opinión, 2016, Vol. 89, p. 1-5. http://www.revistas.espol.edu.ec/index.php/ fenopina/article/view/159

IBÁÑEZ, A. La incorporación de Aisén a la vida nacional 1902-1936. Instituto de Historia de la Universidad Católica de Chile, 1972-1973, Vol. 11, p. 259-378. http://www.memoriachilena.gob.cl/602/ w3-article-71193.html

IREN. Informe N II: La Minería en Aysén. Instituto de Investigación de Recursos Naturales, Santiago de Chile,1966.

LEFF, E. Saber Ambiental: Sustentabilidad, Racionalidad, Complejidad, Poder. Ciudad de México: Siglo Veintiuno Editores, 1998. 
MARTÍNEZ ALLIER, J. El Ecologismo de los Pobres: Conflictos Ambientales y Lenguajes de Valoración. Barcelona: Icaria Editorial, 2004.

MARTINEZ, E. La Evangelización de Aysén: Actores, Características y Dificultades. Puerto Aysén: Vicariato Apostólico de Aysén, 2015.

MEMORIA CHILENA: BIBLIOTECA NACIONAL DE CHILE. La Guerra de Chile Chico o los Sucesos del Lago Buenos Aires. Memoria Chilena: Biblioteca Nacional de Chile, 1999. (Consulta: 04/05/2020). http://www.memoriachilena.gob.cl/602/w3-article-8483.html

MOVIMIENTO APOSTOLICO MANQUEHUE. Antolín Silva Ormeño. Movimiento Apostólico Manquehue, 2020. (Consulta: 05/05/2020). http://www.manquehue.org/patagonia-area/antolin-silva-ormeno/

MOVIMIENTO APOSTOLICO MANQUEHUE. El poblamiento de Aysén. Movimiento Apostólico Manquehue, 2020. (Consulta: 02/05/2020). http://www.manquehue.org/patagonia-area/el-poblamiento-de-aysen/

NIXON, R. Slow Violence and the Enviromentalism of the Poor. Cambridge (Massachusetts): Harvard University Press, 2011.

URETA, S, MONDACA, F y LANDHERR, A. (Sujetos de Desecho: Violencia Lenta e Inacción Ambiental en un Botadero Minero Abandonado de Chile). En Canadian Journal of Latin American and caribbean Studies, 2018, p. 337-355.

VALLEJOS A. (Conflictos, Riesgos e Intervención Socioambiental: Una aproximación sociológica, Simposio Sociología y Medio Ambiente). En: IX Congreso Español de Sociología, Madrid, España, 2017. 
